\section{Rhinoviren setzen Kinderlungen zu}

\author{
Bei vielen Kindern sind Infektionen mit Rhinoviren (RV) Auslöser für \\ Wheezing-Attacken bzw. akute Asthmaexazerbationen. Inwieweit \\ diese Infektionen aber den weiteren Verlauf der Asthmaerkrankung \\ beeinflussen, ist noch nicht klar.
}

- $\mathrm{i}$ in australisch-südafrikanisches Forscherteam untersuchte 50 Kinder im Alter zwischen 4 und 12 Jahren, die wegen einer Asthmaexazerbation in die Notaufnahme eingewiesen worden waren. Bei jedem Kind wurden der „peak expiratory flow" (PEF) ermittelt, ein nasales Aspirat genommen und das Vorliegen einer Atopie durch Pricktests überprüft. Das Nasensekret wurde mit Hilfe von PCR-Assays auf RV-DNA sowie DNA von Respiratory Syncytial Virus (RSV) getestet. Die Kinder sollten nach 6 Wochen und nach 6 Monaten erneut untersucht werden.

Bei 37 (74\%) der Kinder lag eine Atopie vor. RV-DNA wurde bei 41
(82\%) und RSV-DNA bei sechs (12\%) Kindern nachgewiesen. Von den $41 \mathrm{~Pa}$ tienten, die nach 6 Wochen erneut untersucht werden konnten, war der RVDNA-Nachweis noch bei 18 (41\%) positiv. Nach 6 Monaten ließ sich noch bei vier $(22 \%)$ von nun insgesamt 16 Kindern RV-DNA nachweisen - dies war auch der Fall bei zwei $(22 \%)$ von neun Kindern einer Kontrollgruppe mit stabilem Asthma.

Der PEF-Wert war bei allen Kindern mit akutem Asthma vermindert. Es gab keine Korrelation zwischen dem PEF und dem Vorliegen eines bestimmten Virustyps. Bei den Patienten allerdings, bei denen RV-DNA sowohl in der Aufnahmeuntersuchung als auch nach 6 Wochen nachgewiesen wurde, waren die PEF-Werte signifikant niedriger als bei Kindern mit einem RVDNA-Nachweis zum Zeitpunkt der akuten Exazerbation, aber negativem DNA-Befund nach 6 Wochen. In Regressionsanalysen ließ sich die Persistenz der RV-DNA mit dem Ausmaß der PEF-Absenkung assoziieren, nicht aber mit den Ergebnissen der Pricktests.

Fazit: Bei Kindern mit akuter Asthmaexazerbation liegen sehr häufig Infekte mit Rhinoviren vor. Bei über $40 \%$ der Fälle ist die DNA der Viren auch noch 6 Wochen später nachweisbar. Diese Patienten weisen nachhaltige respiratorische Einschränkungen auf, was auf einen Zusammenhang zwischen der Schwere der Exazerbation und der Schwere der Virusinfektion hinweist. $b k$

Kling S et al. Persistence of rhinovirus RNA after asthma exacerbation in children. Clin Exp Allergy 2005; 35: 672-8

\section{Eine neue Option bei Asthma?}

\section{Eine neue antientzündlich wirksame Stoffgruppe sind die Phospho- diesterase-Typ-4-Inhibitoren. Eine Substanz aus dieser Gruppe ist Roflumilast, dessen Wirksamkeit jetzt bei Patienten mit Asthma bronchiale untersucht wurde.}

$\mathrm{n}$ einer doppelblinden plazebokontrollierten Studie mit dreifachem Cross-over-Design erhielten 23 Patienten mit leichtem Asthma randomisiert einmal täglich entweder $250 \mu \mathrm{g}$ bzw. $500 \mu \mathrm{g}$ Roflumilast oder Plazebo über jeweils 7-10 Tage und wechselten dann nach einer Auswaschperiode die Therapie. Am Ende einer jeden Behandlungsperiode wurde eine Allergenprovokation, gefolgt von einer FEV1-Messung, durchgeführt.

Durch die Behandlung mit Roflumilast reduzierte sich die verzögerte Asthmareaktion unter der 250- $\mu$ g-Dosierung um $27 \%(\mathrm{p}=0,0110)$ und um

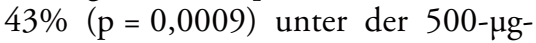
Dosierung, jeweils im Vergleich zu Plazebo. Im Gegensatz zur Therapie mit
Glukokortikoiden zeigte sich auch eine mäßige Beeinflussung der allergischen Sofortreaktion. Sie reduzierte sich unter der niedrigen Roflumilast-Dosierung um 25\% ( $\mathrm{p}=0,0038)$ und unter der höheren um 28\% ( $\mathrm{p}=0,0046)$. Eine direkte bronchodilatatorische Wirkung hat Roflumilast allerdings nicht. Die Therapie war gut verträglich, die meisten Nebenwirkungen waren mild und konnten nicht eindeutig auf die Studienmedikation zurückgeführt werden.

Fazit: Der Phosphodiesterase-4-Hemmer Roflumilast unterdrückt bei Patienten mit leichtem Asthma v. a die verzögerte Reaktion, was auf einen antientzündlichen Effekt hinweist. Der korre-

\section{Steckbrief Roflumilast}

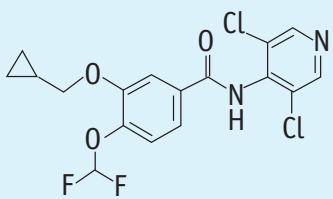

Roflumilast hemmt das Enzym Phosphodiesterase der Isoform 4, das überwiegend in der Lunge lokalisiert ist. Dadurch wird die Hydrolyse von zyklischem AdenosinMonophophat (CAMP) verhindert und damit so auch eine Entzündungsreaktion inhibiert. Denn cAMP hemmt u.a. Proliferation und Chemotaxis inflammatorischer Zellen, verhindert proinflammatorische Zellaktivitäten wie die Phagozytose und unterdrückt die Freisetzung von inflammatorischen und zytotoxischen Substanzen.

lierende klinische Effekt auf Lungenfunktionsparameter ist dosisabhängig. $b k$

Schalkwyk E van et al. Roflumilast, an oral, once-daily phosphodiesterase 4 inhibitor, attenuates allergen-induced asthmatic reactions. J Allergy Clin Immunol 2005; 116: 292-8 